\title{
Cultural Politics of Climate Change: Interactions in Everyday Spaces
}

\author{
Maxwell T. Boykoff, Michael K. Goodman \\ AND IAN CURTis
}

\section{INTRODUCTION}

In this chapter, we connect the more formal spaces of climate science, policy and politics operating at multiple scales to those of the spaces of the "everyday'. Climate change is a high-stakes, high-profile and highly politicized issue that relates - often in messy, non-linear and diffuse ways - to people's everyday lives, lifestyles and livelihoods. It is no longer thought of merely as scientific issue; rather, the 'climate question' is considered one that now, more than ever, permeates our individual, as well as shared, economic, political, cultural and social lives. Through a brief accounting of these interactions, we explore some interesting and notable spaces comprising what we see as the emerging cultural politics of climate change at the scale of the everyday discourses, representations and "popular" cultures that work to engage society.

By cultural politics we mean those oft-contested and politicized processes by which meaning is constructed and negotiated across space, place and at various scales. This involves not only the representations and messages that gain traction in discourses, but also those that are absent from them or silenced (Derrida 1978; Dalby 2007). In these spaces, discourses are tethered to positionalities, material realities and social practices (Hall 1997). As David Harvey has commented, 'struggles over representation are as fundamental to the activities of place construction as bricks and mortar' (1990, 422, emphasis added). By examining these features as manifestations of ongoing and contested processes, we can consider questions regarding how power flows through the capillaries of our shared social, cultural and political body, constructing knowledge, norms, conventions, truths and untruths (Foucault 1980). Such dynamic interactions form nexuses of power-knowledge that shape how we come to understand things as 'truth' and 'reality' and, in turn, contribute to managing the conditions and tactics of our social lives (de Certeau 1984). However, rather than brash imposition of law or direct disciplinary techniques, we consider how more subtle power-knowledge regimes in, for example, the likes of the arts, sports and celebrities, permeate and create what becomes 'permissible' and 'normal' as well as 'desired' in everyday discourses, practices and institutional processes (Foucault 1977). 
Specifically here, the discursive and material elements comprising a cultural politics of climate change are inextricably shaped by ongoing environmental processes and those of the science of climate change. This has been described as the inseparable dialectic of nature and culture (Cosgrove 1983). Nature is not a backdrop upon which heterogeneous human actors contest and battle for epistemological and material successes. Rather, (scientific) meaning is constructed, maintained and contested through intertwined socio-political and bio-physical processes (Blaikie 1985; Whatmore 2002). Meaning is constructed and manifested through both the ontological conditions of nature and contingent social and political processes involved in interpretations of this nature in the processes and politics of science (Robbins 2004). Approaching these spaces of the cultural politics of climate change in this way helps to interrogate 'how social and political framings are woven into both the formulation of scientific explanations of environmental problems, and the solutions proposed to reduce them' (Forsyth 2003, 1). These 'framings', then, are inherent to cognition, and effectively contextualize as well as 'fix' interpretive categories in order to help explain and describe the complex environmental processes of climate change (e.g. Robbins 2001). Thus, particular framings serve to assemble and privilege certain interpretations and understandings over others (Goffman 1974; Entman 1993) and this has certainly been the case with the highly-charged discourses surrounding climate change.

Given the increasingly obvious societal attention to the urgencies of climate change, it might not be a surprise that the discourses and associated praxis of 'dealing' with climate change have so rapidly filtered into the spaces of the everyday. Rather, what is surprising is how widespread and indeed 'mainstreamed' the discourses of climate change are at this particular moment. Indeed, through all sorts of media forms - from newspapers and books, to television and films, to radio and the internet - a diverse groundswell of actors and institutions are bringing climate change 'home' (Slocum 2004) by encouraging us to change and improve daily routines, practices and lifestyles that impact the global climate. The Live Earth slogan of 'One world, One climate, Be the change' has at its base the desire to primarily motivate individuals to do 'something' for the climate in their daily lives. Here, the installation of compact-fluorescent light bulbs in one's house or at work has become the most iconic of 'somethings' to do (see Hobson 2006; Slocum 2004); this is taken up further below.

Many climate change campaigns see the everyday much as it perhaps should be seen: "there is nothing "natural" or "inevitable" about everyday life [... ] it reveals itself as complex and processual rather than simple and reified' (Paterson 2006, 7). Indeed, it might be argued that this is precisely why these campaigns have focused on the spaces and praxis of the everyday and, in combination, why they have moved so heavily into the realms of popular culture like MTV, which are predominantly designed to shift consumer consumption behaviours towards more sustainable ends. In regards to ethical consumption - a subset of the broader category of sustainable consumption 
(Hinton and Goodman, forthcoming) —Clarke et al. have commented, '[e]thical consumption campaigning redefines everyday consumption as a realm through which consumers can express a wide range of concerns and engage in a broad set of projects, including social justice, human rights, development or environmental sustainability' (2007, 241). Yet, several critical issues stand out-especially with respect to climate change - in not only what gets defined and constructed as the 'right' or 'moral' actions to take or the scale at which they are pitched, but in how these campaigns are put together and enter the public realms of cultural politics.

As above, these discourses construct their own power-knowledge regimes that can, perhaps, be critically assessed: Why the massive focus on switching over light bulbs rather than some other activity? Why not no/less consumption rather than different consumption in its green/ethical forms? For example, why not no car instead of a hybrid car? More generally, why is consumption elevated and entrenched-now, in academic work as much as any other media - as the axis of engagement concerning climate change for civil society? Where might more fundamental structural changes lie in this and other discourses and narratives on sustainable and ethical consumption? In short, there is theoretical/conceptual as well as empirical/material need to consider the political economic realities that not only construct people's everyday lives through (very often unequal) material and structural relationships, but, in particular here, the 'everyday' inequalities many experience in their access, understanding and abilities to respond to climate change campaigns.

If anything, the cultural politics of climate change are rife with ambiguities and ambivalences, conflicts and contradictions that complicate not only their actual material and 'real' effectiveness, but their role in doing that 'something' for the climate. For instance, communicating climate change through popular culture - celebrities, movies, popular music - can easily work to sensationalize the issues and act as distractions as much as it can bring in new 'eyes' and 'ears' to the salient issues. Making climate change an everyday, individualized issue - e.g. 'Be the change' - can, on the one hand, empower individuals and create and foster emergent movements through these 'singularities' (Clarke et al. 2007), but at the same time it can work to unfairly 'responsibilize' (Guthman 2007) and socialize climate change problems and solutions at the level of the individual and consumers at the expense of holding states, institutions and corporations accountable. Individualization can work to simultaneously atomize social, economic and environmental changes and movements at the same time it might open up space for the development of a more 'cosmopolitan ethic' (Popke 2006, 2009) by suggesting that by 'being the change', individuals/consumers are connecting to and creating a 'better' planet. Given that shifting to more 'climate neutral' consumption - e.g. 'low carbon'/meatless diets, hybrid cars, the purchase and installation of fluorescent light bulbs - is what is very often recommended, it is argued that it is through these acts of more sustainable consumption choice that this cosmopolitanism and/ or 'ecological citizenship' can be enacted on an everyday basis (i.e. Seyfang 
2005; see also Sassatelli 2006). Thus, for better or worse, the figure of the globalized climate change 'consumer-citizen' can seemingly be created, fostered and furthered through a simple trip to the shopping mall, local store and/or supermarket, attendance at a football game, or by just flicking off (or on as the case may be) the television.

Below we explore how, in the development of the cultural politics of climate change, the spaces, places and processes of the everyday are increasingly powerful and transgressive - yet also fundamentally ambiguous and problematic - in the discourses and materialities that surround climate change and its highly politicized amelioration. We first touch on some contemporary turns in the realms of businesses and environmental non-governmental organizations (ENGOs). We then address the burgeoning arenas where popular culture-particularly through the arts, music, film and sport-has taken up climate challenges and opportunities for engagement with much wider 'audiences' than heretofore. Given the confined spaces of this book chapter, we have limited ourselves to select examples that we find help illuminate how cultural politics are engaging with climate change politics in a range of interactive, uncertain and potentially fraught ways.

\section{WHO SPEAKS FOR THE CLIMATE, NOW?}

The cultural politics of climate change construct and exist in a multitude of rapidly expanding spaces. A prominent link between these spaces is mass media, from entertainment to news, the representations of climate change shaping perceptions and considerations for action. In the last decade, there has been a significant expansion from consumption of traditional mass media-broadcast television, newspapers, radio-into consumption of 'new media', such as the internet and mobile phone communications. This movement has signalled substantive changes in how people access and interact with information, who has access, and who these "“authorized definers" of climate change' are (Carvalho 2007, 232). In tandem with technological advances, these communications are seen to be a fundamental shift from 'one to many' (i.e. one-way) communications to 'many to many' (i.e. more interactive webs of communications). Together, these media are constituted by a diverse and dynamic set of institutions, processes and practices that together serve as 'mediating' forces between communities such as science, policy and public citizens. Members of the communications industry and profession-publishers, editors, journalists and others-produce, interpret and communicate images, information and imaginaries for varied forms of media consumption. Thus, the reporting and communication of climate change science and policy, in particular, is not just the innocent reporting of scientific 'facts' and 'truths' (Boykoff and Boykoff 2004; McChesney 2008).

By way of numerous tributaries (outlined by Heike Schroeder, Chapter 2), climate science and governance has flowed into public view with significant attention through mass media since the 1980s (Carvalho and Burgess 2005). 
A number of key factors contributed to this trend. Amongst them was NASA scientist James Hansen's testimony to the US Congress in the summer of 1988, during the time of an intense heatwave and drought across North America. Also, in the United Kingdom, Prime Minister Margaret Thatcher spoke to the Royal Society in what became known as her 'green speech' on the dangers of climate change. Meanwhile, early climate governance became operational as a 46-country climate conference took place in Toronto, Canada and the United Nations Intergovernmental Panel on Climate Change (IPCC) began its work. These high-profile interventions-turned-spectacles generated substantial attention and became emblems for newfound public concern on the issue (Boykoff and Boykoff 2007). As this issue first unfolded in the public sphere, climate scientists were widely canvassed as the predominant 'claims makers'. Yet, in addition to climate science 'speaking' on behalf of the climate, carbon-based business and industry interests and ENGOs grappled for their particular discursive and material 'locations' from which to address climate challenges. Many of the struggles to represent climate change in the 1980s and 1990s were dominated by carbon-based energy businesses and ENGOs (Gottlieb 2002). Here, then, in the process of understanding changes in the climate, many entities, organizations, interests and individuals battled to shape not only the science but fundamentally the awareness, engagement and possible actions around the climate agenda. Indeed, as John Street $(2004,445)$ has commented on the growing connections between politics and popular culture, '[re]presentation, whatever the principles or ethical values informing it, does not reflect the world so much as organize knowledge about it', and, as we might add here, it does so in very politicized and politicizing ways.

From early on, the variously embattled efforts to define the "climate question' and frame the problems, predicaments and possibilities have expanded to today's tremendous variety of 'actors', (everyday) actions and numerous media forms. Subsequent to the 18th-century English-led Industrial Revolution and its 'dark satanic mills', 'progress' has often been defined by the carbon-based technological advancements driven by the engines of coal, oil and natural gas. Yet, beginning even in the late 1800s, scientists such as Svante Arrhenius, G.S. Callendar, Gilbert Plass and others began making links between greenhouse gas (GHG) emissions from energy production and increases in atmospheric temperature as well as other climatic changes (Weart 2003). As further and extensive scientific work coalesced on basic points that the climate was changing and that humans played a part in such changes, early actors responded to these findings. In terms of business, some adapted and changed practices, while others called such research into question. Meanwhile, many ENGOs - such as Greenpeace, Friends of the Earth, Oxfam and the Natural Resources Defense Council-sought to raise public awareness and policy-actor concern regarding 'negative externalities' of environmental damage and risk from climate change. On this dynamic battlefield of competing knowledges and representations, predominantly US-based think tanks influenced by conservative ideologies - and often funded by the 
carbon-based industry-amplified uncertainties regarding various aspects of climate science, de-emphasized the human contribution to climate change, and called attention to the costs of action, such as mode-switching to renewable energy sources. These messages were repeated in multifarious ways, through subtle scientific 'certainty' argumentation methods (Freudenburg et al. 2008) to more deliberate politics of manipulation (McCright and Dunlap 2003; Oreskes et al. 2008) to overtly deceptive disinformation campaigns and initiatives (Gelbspan 1998; Beder 2002). In turn, these controversial narratives and media campaigns have been found to not only dampen social movements for change (e.g. Norgaard 2006), but to also inspire and catalyze (e.g. Moser and Dilling 2007) action in the realms of environmental politics and movements, from the more 'mainstream' efforts of large ENGOs to more grassroots, direct-action efforts such as the 'performance spaces' of Climate Camp based in the United Kingdom (see climatecamp.org.uk) (see also Moser in Chapter 9).

In the last decade or so, questions raised across this spectrum have largely moved away from 'is the climate changing?' and 'do humans play a role in climate change?', to more textured considerations of how to effectively govern the mitigation and adaptation alternatives. While these newfound challenges have enrolled actors from other spaces such as popular culture, business groups, ideologically-driven think tanks and ENGOs have continued to vigorously debate and discuss associated features and consequences of climate mitigation. For example, as businesses have touted 'carbon neutrality' in their practices, some ENGOs have praised such activities as a first awareness-raising step towards ongoing decarbonization of industrial practices, while others have fiercely critiqued these claims as 'greenwashing' business-as-usual actions. Similar debates also hold for questions regarding 'voluntary carbon offsets' for carbonunfriendly travel, carbon labelling of food and household products, movements towards 'low carbon diets' by purchasing local goods and the inherent paradoxes of calling on 'clean coal' technologies to reduce GHG emissions.

While these various initiatives and plans have gained traction in recent years in the everyday lives of many, important critiques have emerged regarding the dangers of an emergent 'carbon capitalism' associated with commodifying the atmosphere, and the fixation with market mechanisms as primary tools to 'answer' climate questions (Newell and Paterson, in Chapter 5). Indeed, these solutions have been deemed problematic to the extent that, at their core, these activities 'render the messy materiality of life legible as discrete entities, individuated and abstracted from the complex social and ecological integuments' (Prudham 2007, 414). Thus, in the rapidly-expanding, dominant market-oriented approaches of carbon capitalism (Bumpus and Liverman 2008), decarbonization is seemingly reduced to the simple matter of neoliberal (political) economy that, now more often than not, is defined by shifts in consumer choice and activism.

While carbon-based industry interests have consistently been pilloried for defending their political economic interests over social and environmental concerns, these landscapes have certainly become more nuanced in recent 
years across a range of scales and spaces. Examples include large-scale cooperative efforts such as the World Business Council for Sustainable Development, to more local initiatives such as the Energy4All wind farm cooperative in the United Kingdom. Another example of a local project is the Eco-Renovation initiative in Oxfordshire, England, which is a cross-sectoral community-based enterprise to promote significant low carbon refurbishment of local homes. Participants open their homes to the public on designated weekends to exhibit these re-designs, and thus demonstrate how local suppliers and installers have worked to reduce GHG emissions at the household level. This project links into a burgeoning array of organizations and initiatives throughout the region and illustrates the rapidly expanding engagement in the public sphere with climate change mitigation challenges.

While scientists, businesses and environmental groups have populated the discursive spaces of the climate change issue through mass media since the 1980s, there has emerged a broader spectrum of voices in recent years. This does not mean that scientists and others have 'stopped' speaking; rather, in the public sphere within which climate science and politics find meaning in our everyday lives, the boundaries between who constitutes an 'authorized' speaker (and who does not) has expanded (e.g. Gieryn 1999; Eden et al. 2006). In so doing, these spaces have been increasingly infiltrated by new 'actors' in the Shakespearian global stage; these influences have changed the architecture and processes propping up and perpetuating a cultural politics of climate change.

\section{THE CLIMATE CHANGE CULTURE INDUSTRY}

\section{Sculpting, Crooning and Blogging for Change: Art, Movies, Music and the Web in Climate Change Debates}

While some of the spaces comprising popular culture have been dismissed as mere distraction (e.g. Weiskel 2005), these can in fact be potent yet also fraught opportunities to reach places where many citizens reside, discursively, materially and cognitively. Herein lays the contested nature of these expanded interactions. As an example of these conflicts, at the November 2008 launch of his 'culture strategy', conservative London Mayor Boris Johnson embodied the promises and perils of such boundary work. In his remarks, Johnson argued that, 'arts chiefs must stop dumbing down culture for young people'. According to reporter Ian Drury (2008), 'the mayor of London pledged to stop targeting [young people] with hip-hop music and movies, and instead encourage them to enjoy opera and ballet'. Importantly, this raises questions regarding whether such channels of communication might reach people where they are or where others think they should be. Yet, more fundamentally, Johnson's comments highlight how political actors are prepared to wield and negotiate the contours of (popular) culture as a key means to various cultural and political economic ends, in this case to try to foster greater cultural awareness in the lead up to the London 2012 Olympics. 
Today, many musicians, artists, athletes and actors are increasingly involved in climate change initiatives. Some have focused their energies in what has traditionally been characterized as 'high culture'. For example, London choreographer Siobhan Davies has developed the performance Endangered Species where semi-human forms perform inside museum display cases to evoke notions of fragility and survival. Similarly, British sculptor Antony Gormley worked with human images in ice to demonstrate the ephemeral nature of human existence as part of a Cape Farewell project and expedition. These activities have been associated with a wider project begun in 2005 entitled 'TippingPoints: A climate scientist and artist's encounter'. The TippingPoint initiative arose amongst practising artists, automotive designers and engineering academics. While these endeavours have met a great deal of critical acclaim, others have argued that they enjoy a relatively limited reach beyond 'high culture' and the traditional art form.

Other engagements in the cultural and political landscapes of climate change include those through more 'popular' forms of mass media. In particular, the 2006 release and success of the powerpoint-turned-documentary film 'An Inconvenient Truth' (hereafter AIT) featuring Al Gore has been an illustrative watershed moment in the shifting politics of climate change as they meet popular culture (cf. Luke 2008). Mass media around the planet analysed, commented on and reported various facets of the film, from the content and substantive issues the film raised, to its 'celebrity-meets-science' spectacle. In so doing, stories spanned straight news reporting to entertainment culture 'buzz' (Seabrook 2000), thereby further expanding the climate question into other transgressive spaces and places. For instance, in the Washington Post's major coverage of the movie, a substantial article was produced for the Style section of the newspaper that reported on the red-carpet premiere in the USA without even a touch of irony or deviation from other movie premiere event reporting. Interestingly, movie-goer Jessica Simpson's 'black pantsuit, pearl earrings [and] hair tucked conservatively in a loose bun' (Argetsinger and Roberts 2006, C3) was elevated to a level of relevance on par with the film's depiction of the potentially cataclysmic environmental outcomes of climate change. Such past and current mass-media cross-pollenization contributed to the claim by $89 \%$ of AIT filmgoers that they became more aware of climate change causes and consequences, while $74 \%$ of this same group claimed they were taking action to address climate change as a direct result of viewing the movie (AC Nielsen 2007).

Further engagements are taking place in the 'convergence cultures' (Jenkins 2006) of music, television and the internet. Begun in earnest through the Al Gore-sponsored Live Earth concerts of 2007, musicians have begun to incorporate climate change-themed lyrics and images into their songs and videos. One of the most prominent in this regard would be Madonna, who not only released her single 'Hey You' to coincide with the Live Earth climate change 'event', but has continued on this theme with ' 4 Minutes to Save the World' which includes contributions by the enormously popular Justin Timberlake and Timbaland. 
More specifically, Madonna's songs contribute directly to some of the ambiguities circulating in these everyday discourses and representations of climate change. On the one hand, both work to inscribe the individualism, personalization and responsibilism of much of the climate change discourse into the lyrics: 'Hey You' is peppered with the refrains (amongst others) of:

Hey you, don't you give up

It's not so bad, there's still a chance for us ...

Hey you, open your heart

It's not so strange,

You've got to change this time.

The song - spliced with the performers jumping in and out of old cars surrounded by supermarket shelves and a clock ticking down in the background-continues with:

We only got four minutes, huh, four minutes,

So keep it up, keep it up, don't be afraid,

You gotta get 'em a heart,

Tick tock tick tock tick tock'.

Both sets of lyrics seem to open up space for 'us' to do our own personally transformative 'somethings' - from being persistent and brave, to compassionate and hopeful - about the apparently disconnected, depressing and overwhelming problems of global climate change.

On the other hand, the video for 'Hey You', sends a slightly different message; it directly intersperses images of climate-based environmental catastrophe and poverty with those of world leaders such as Gordon Brown and George W. Bush, who have the lyric 'hey you!' juxtaposed over their images. Here the 'you' being referred to in the song might not only be these specific individuals, but might also be a way of imploring 'us' to hold these powerful leaders accountable through more traditionally political or direct-action means. Yet, both interpretations of Madonna's engagements with climate change politics are somewhat contradicted by the fact that she herself has been called a 'climate-change catastrophe' given the large amount of carbon emissions associated with her personal and professional life (hippyshopper. com 2008).

Different musicians have engaged in yet other ways. Thom Yorke, the lead singer of Radiohead, was not only the face of the Big Ask-Friends of the Earth's campaign to get the United Kingdom Government to change its climate policy - but has pledged to reduce the carbon footprint of the band by shipping tour equipment on boats and reducing the band's touring schedule. Both Coldplay and Pearl Jam have pledged to be 'carbon neutral' on their various tours and albums by purchasing offsets to reduce their carbon footprint. At the same time, all three work to organize fans by having booths 
from environmental campaigns on tour, as well as speaking on climate-related issues in the mass media and to fans. Also engaged in this area is a Londonbased ENGO known as Julie's Bicycle which, since 2007, has deliberately worked 'backstage' to build capacity and motivation amongst music industry players. Formed by a group wanting to find ways to reduce the carbon footprint of the British music industry, the organization has sought to be an example to other entertainment sectors as well as in other countries. Key features of Julie's Bicycle (as with TippingPoint) are the direct links it has forged with climate and environmental scientists. These elements seek to emphasize and cement the scientific foundations of the organization, rather than place a focus on explicit climate campaigning.

In still other media arenas and working across myriad mass media formsfrom the internet and user-generated message boards, to music, television and celebrity spokespeople - the United Kingdom ENGO Global Cool has taken to popular culture in order to raise awareness amongst younger generations and offer them 'practical solutions' to climate change. As they put it:

Global Cool is the climate change charity to get you inspired. We want you to feel good about doing good. [ ... ] Global Cool will show you that saving the planet isn't just for the people who like to think of themselves as 'green'. We give you practical advice on the things you can do that will make a positive difference. [ ... ] And we're not going to preach. We won't lecture you on melting ice caps. We're not asking you to live in a cave or give up all the good things in life. We're here to show you that you can lead a fun, exciting life and do your bit for the environment, with a few tweaks to your lifestyle and a little help from our celebrity friends.

(Global Cool 2009)

One of the more unique efforts by Global Cool was to get the DJ Erik Prydz to help with a music video entitled 'Proper Education' featuring a remix of Pink Floyd's 'Another Brick in the Wall' paired with school kids on a publichousing estate secretly installing compact fluorescent bulbs into unaware residents' flats. At the end of the video, there appears a tag-line reading 'you don't need a proper education to save the planet'. Speaking about the project, Prydz explains:

There was a lot of anticipation around this video and I was really keen to do something a bit different. [ ... ] Pink Floyd would always use their videos to get a message across and I really wanted to carry on this spirit. I'd been reading so much in the press about climate change and global warming recently and felt it would be great to try and empower people to do something about it. It's not making a grand statement. It's just simply saying everyone can do a little and it will make a difference.

(The Inspiration Room 2009a) 
A wider description of the project states that:

The video, directed by Marcus Adams, saw Prydz consult with climate change charity Global Cool. Global Cool believes that the solution to defeating global warming lies within the power of the individual, empowering them to take personal action to make a valuable difference. Global Cool spokesman, Dan Morrell said, 'The message is clear, climate change is happening but collectively, given the tools and the knowledge to actively reduce $\mathrm{CO} 2$ emissions, and to encourage others to do the same, we can collectively push the climatic tipping point long into the future'.

(The Inspiration Room 2009a)

Indeed, in the cultural politics of climate change-seen here, and in other examples in the chapter - there is the problematic tendency to lionize and entrench the acts of individuals primarily as consumers at the expense of more critical considerations of citizenship, amid powerful carbon-based political economies. Here, although Global Cool works to open space for individuals to do something about climate change, through these methods they elevate voluntaristic and individualized forms of engagement and climate change problem-solving.

Finally, MTV has also got into the climate change 'act' through its 'MTV Switch' campaign. Similar to Global Cool's multimedia approach, but based much more around its television empire, MTV Switch operates through 'public service announcements' (PSAs) that work 'to promote environmentally-friendly lifestyle choices amongst youth in order to reduce the carbon emissions that contribute to climate change' (MTV 2009). Centred on celebrity shorts from, for example, the likes of Cameron Diaz and video feature spots developed by some of the world's leading-edge marketing firms (who did the work pro bono), the main hub of the campaign is the website (www.mtvswitch.org) which contains access to the videos, has a user-generated weblog (or blog), news, downloads and a carbon footprint calculator hosted at the Global Cool website. Not surprisingly, the focus, again, is on shifting individuals towards 'simple climate conscious acts' much like the Global Cool campaign:

Everyone, no matter what age or where they live, can take action to reduce their carbon footprint. The MTV SWITCH PSAs seek to entertain, intrigue and inspire viewers to take on simple climate conscience acts such as unplugging mobile chargers and turning the thermostat down one degree.

(MTV 2009)

Further, much like not needing a 'proper education' to do something for the climate, one PSA in particular - the aptly named 'Green Song' (The Inspiration Room 2009b) - argues that 'greenwashing' is so prevalent that one shouldn't (have to) be 'green' to be 'green': 
Politicians feed us crap, celebrities are the same,

It's all about how green they are and who deserves the blame;

How green you are not how much you give,

How loved you are is how you live,

So know your greens and think a bit,

Because you don't have to be green to be green.

That MTV is airing videos arguing we shouldn't trust 'green' celebrities, many of whom are the very face of MTV Switch itself, is not only deeply ironic - if not passing straight into parody and, indeed, absurdity - but it should tell us that, at the least, this 'celebritization' of climate change (see Boykoff and Goodman 2009) thoroughly delineates the mainstream of the contemporary cultural politics of the environment. While we address this overt 'spectacle-ization' of climate change much more below, we now turn to look at the growing connections between sport and climate change mitigation.

\section{Sport}

In recent years, many climate change initiatives have developed in the realms of sport with many organizations, institutions and individuals increasingly addressing various aspects of the climate question. The majority of the activities have focused on climate mitigation, but an increasing number of endeavours are addressing adaptation questions, such as those involving how various sporting activities can continue in a changing climate. Many of these programmes to date have been taking place in Europe. At the 2006 World Cup in Germany, there were a number of Fédération Internationale de Football Association (FIFA) initiatives aimed at reducing emissions related to the tournament, from generating energy for the stadium in Hamburg from renewable biogas to reduced fares on the German Railway - called 'World Champion Tickets' - for taking public instead of private transport to the various matches around the country. Furthermore, over the 2007-8 English Football Association (FA) Cup Tournament, the league sponsored a voluntary initiative that they called 'Carbon Footyprint'. In this initiative, supporters were to pledge to reduce their GHG emissions as they travelled to FA Cup matches, and to reduce emissions in other aspects of their daily lives. As they did so, if they documented these actions through the FA website, they would push their favourite club up the Footyprint table. In addition, Ipswich Town FC became the first United Kingdom football club to go 'carbon neutral' through a variety of initiatives such as supporter carbon offsetting and greater energy efficiency (Holt 2007). Individuals such as England and Portsmouth FC goalkeeper David James have spoken out about issues of transport, renewables and climate change; James, in particular, has personally converted his automobile fleet to be fully bio-fuel (James 2006), while Manchester United FC manager Sir Alex Ferguson garnered a wave of 
media attention when he took part in an $\mathrm{Al}$ Gore-run climate leadership training session at the University of Cambridge in 2007 (Adam 2007).

In North America, a significant moment addressing climate change through sport came in the form of a Sports Illustrated special issue in March 2007 entitled 'Sports and Global Warming: as the planet changes, so do the games we play - time to pay attention'. The cover story focused on adaptation to climate change and began with the following warning:

As global warming changes the planet, it is changing the sports world. To counter the looming environmental crisis, surprising and innovative ideas are already helping sports adapt.

(Wolff 2007, 36)

In terms of mitigation, many North American sports are developing their own initiatives. Through purchasing carbon offsets, the National Football League staged a 'Carbon Neutral Superbowl' in 2007 (Davidson 2007) and Major League Baseball announced - in co-ordination with the National Resources Defense Council - that it was 'going green' through various activities and programmes (Bowen 2007). Similarly, in March 2008 Japanese Baseball announced plans to 'green' the sport by shortening the time of games by $6 \%$ (or 12 minutes) in order to save energy from lighting (Associated Press 2008).

These various activities have developed, interacted and gained greater coordination in recent years. Prominently, a United Nations Environment Programme (UNEP) initiative has organized conferences on the theme of sport and the environment since 2001. Called the 'Global Forum for Sport and the Environment' (G-ForSE), the fifth meeting was held in Alicante, Spain in October 2008 with a focus on climate change. Also, at the 14th United Nations Conference of the Parties meeting (COP-14) in Poznan, Poland in December 2008, top Olympic snow skiers presented a petition to negotiators which read, '[i]ce and snow are particularly vulnerable to the impacts of global warming, and as avid skiers and snowboarders we see our beloved sports endangered' (Roddy 2008). However, it is worth noting that not all sports activities will necessarily 'lose' from anticipated climate changes. In particular, a 2006 study from the Journal of Leisure Research concluded that the typical golfer in Toronto, Ontario will play in climate conditions like they are in Columbus, Ohio by the year 2080 (Scott and Jones 2006). Irrespective of rainfall extremes and sea-level rise, perhaps mogul Donald Trump has made a sagacious move in the golfing world by investing in a course back in golf's birthplace of Scotland, where year-round play might just become the norm by 2100 !

\section{Glamorous Politics?: The Celebritization of Climate Change}

The preceding discussion can be connected and taken further through an analysis of how a range of celebrities - the new 'charismatic megafauna' in climate change debates - are populating the discourses on possibilities for 
climate governance and everyday mitigation/adaptation action. In contemporary society, celebrities undoubtedly have amplified voices and garner increased attention in the public purview (Marshall 1997; Street 2004). Constituted by interacting and interactive media representations (Littler 2008), celebrities have become the 'intimate strangers' (Schickel 2000) we wish (and are told) to know - and know everything about — at media-ted distances. To capitalize on this 'star power' with respect to a range of environmental issues, discrete organizations - such as the Science and Entertainment Exchange (Lieberman 2009) - have moved to support and improve interactions among celebrities and science, environment and conservation (Brockington 2008).

In efforts to understand and catalogue the growing role of celebrities in connection to climate change, Boykoff and Goodman have developed a 'taxonomy of climate celebrities' (2009). Thus, celebrity voices are defined by six main types of political or social determinants that shape their actions: actors, politicians, sports figures/athletes, business people, musicians and public intellectuals (Boykoff and Goodman 2009). Specific examples include many of the individuals already mentioned, but also Sienna Miller working with Global Cool, Oprah Winfrey through guests and themes on her talk show, Richard Branson as head of the self-proclaimed 'environmentally-conscious' Virgin business empire, and George Monbiot, an activist-journalist who writes and speaks about climate change in the United Kingdom. As Bono, $\mathrm{U} 2$ front man and politicized celebrity extraordinaire, has put it in the pages of Vogue, 'celebrity is a bit silly, but it's currency of a kind'. Indeed, it is a currency that spends (overly) well in the neoliberal spaces carved out by the increasingly marketized, privatized, voluntary and individualized ways of addressing climate questions.

Divergent and ambivalent perspectives on the roles of celebrity-analytical, descriptive and normative - have raised deep-rooted and fundamental concerns about the processes and functions of celebrity, as well as the nature of their influence (Littler 2008; Redmond and Holmes 2007). It is important to ask, can these 'celebrity effects' inspire and foster grassroots, democratic movements and responses to climate change by and for 'the people', or are they plutocratic, unique and extraordinary elite behaviours of distraction that work to build up the celebrity environmental 'brand'? Furthermore, as these questions relate to climate governance and everyday practices, they are arguably as important now as ever before inasmuch as they also lead us to better understand the broader contemporary expansion of celebrities into environmental politics and other realms such as development (e.g. Goodman, forthcoming; Richey and Ponte 2008). Indeed, as Gore optimistically put it speaking to an international climate change conference in 2008:

We have to overcome the paralysis that has prevented us from acting [to address climate change] and focus unblinkingly on this crisis as opposed to spending so much time on OJ Simpson and Paris Hilton and Anna Nicole Smith. 
In uttering this statement, Gore failed to recognize the role of his own type of celebrity, which surely allowed his commentary to pass from the confined spaces of the conference to much beyond the eyes and ears of the delegates and, through the processes of the mass media, into the public realm in a set of discursive pathways reserved for very few individuals engaged in climate change debates. These, perhaps, differing celebrity effects and their shifting contexts, then, beg the following question: When working towards climate change mitigation, is it more effective to plant celebrities than to plant trees? Very much more than a silly glib quip, we feel that this question, in addition to the others exploring the growing connections between climate change and popular culture, should perhaps be one of the fundamental considerations concerning the 'effectiveness' of the current tactics that have and continue to form the contemporary cultural politics of climate change.

\section{CONCLUSION}

In this chapter, we have sought to provide some lines of connectivity amongst the book's contributions by exploring how mitigation and adaptation initiatives as well as arenas of expertise translate into the 'everyday' media spaces of potential citizen awareness and engagement. At a minimum, 'public' space is dynamic and heterogeneous, where 'mainstreaming' processes face a range of responses amongst varied social groupings. In this sense, connections between formal climate policy initiatives and potential behavioural changes are not straightforward: engagement does not merely stem from glamouroriented messaging, but possibilities "for actions are shaped by a range of cultural and political factors. For our purposes here, we see these as places and spaces where meaning, value, power and rhetoric are negotiated through various popular media and mediums and more broadly through cultural politics - what Alvarez et al. $(1998,7)$ refer to as that bundle of processes 'enacted when sets of social actors shaped by, and embodying, different cultural meanings and practices come into conflict with each other'.

Further, the many 'actors' in this theatre of discursive and material structuration - from climate scientists, business industry interests and ENGO activists, to artists, television and movie stars - are ultimately all members of the 'public citizenry'. So, responses to media messaging thereby feed back to varying degrees into ongoing environmental science and policy formulations. In other words, the cultural politics of climate change are situated, powerladen, media-ted and recursive, and should be conceptualized as such. Much like many of the growing list of 'climate change celebrities', those who have power, access and influence are those who have the advantage in this battlefield of knowledges, understandings and interpretations. Here, mass media representations of climate change actors, action, predicaments and progress remain key influences that shape discourses and bounding considerations for possible climate action. These elements may be as important as formal climate governance architectures - such as those currently being constructed in 
the lead up to COP-15 in Copenhagen - to the long-term success or failure of efforts to take carbon out of the atmosphere, or keep it out. To the extent that we fail to examine how these representations and symbols are negotiated through relations of dominance, subordination, and inequalities of access and resources, we miss out on important components of the 'scope of [climate] politics' (Rosati 2007, 996) or the full spectrum of possibilities for future climate mitigation and adaptation action.

The efforts described here focused towards the reconfiguration (or reorganization) of discourses might open up new possibilities for climate change negotiation and action (cf. Swyngeduow 2007). Still, as this chapter has illustrated, these spaces can be as contradictory and problematic as they are complimentary and transgressive. To the extent that Brad Pitt garners interest in green building and energy conservation for readers of Us Weekly in ways that many others - including scientists and sustainability campaigners-likely cannot achieve, we suggest that awareness-raising is a short-term gain. However, voluntaristic and individualized responsibilism by citizens and consumers - and considerations of how shifting consumption patterns may influence climate causes and effects - remains a rather awkward and problematic facet of movements for climate mitigation/adaptation action. How these movements in the cultural politics of climate change will engage with topics such as food choices (e.g. meat consumption) and links to climate change (e.g. through land use) over the medium and long term remain open questions worthy of vigorous discussion. Through the comments on offer here, we aim to provide greater context and insights to facilitate these ongoing dialogues, with a critical eye on what we may expect in the next years in the cultural politics of climate change, and related interactions in the spaces of the everyday. We ignore or dismiss the influence of popular culture in shaping climate politics at our collective peril.

\section{REFERENCES}

AC Nielsen (2007) Global Omnibus Survey, Oxford: AC Nielsen.

Adam, D. (2007) 'The persuaders: Sir Alex Ferguson joins Gore's climate A-team', Guardian 29 March, 11.

Alvarez, S.E., E. Dagnino and A. Escobar (eds) (1998) Cultures of Politics and Politics of Cultures: Re-visioningLatin American Social Movements, Boulder, CO: Westview Press.

Argetsinger, A. and R. Roberts (2006) 'The reliable source', Washington Post, C3.

Associated Press (2008) 'Japan baseball looking to fight global warming with shorter games', Associated Press, 18 March.

Beder, S. (2002) Global Spin: The Corporate Assault on Environmentalism, White River Junction, VT: Chelsea Green Publishing Company.

Blaikie, P. (1985) The political ecology of soil erosion in developing countries, London: Longman Scientific and Technical.

Bowen, T.S. (2007) 'Red Sox turn green', Business Week, 26 October.

Boykoff, M.T. and J.M. Boykoff (2004) 'Bias as Balance: Global Warming and the U.S. Prestige Press', Global Environmental Change 14 (2), 125-36. 
(2007) 'Climate Change and Journalistic Norms: A Case Study of U.S. MassMedia Coverage', Geoforum 38 (6), 1,190-204.

Boykoff, M.T. and M.K. Goodman (2009) 'Conspicuous redemption? Reflections on the promises and perils of the "celebritization" of climate change', Geoforum 40, 395-406.

Brenner, N. and N. Theodore (2002) 'Cities and the geographies of actually existing neoliberalisms', Antipode 34 (3), 349-79.

Brockington, D. (2008) 'Powerful environmentalisms: Conservation, celebrity and capitalism', Media, Culture and Society 30 (4), 551-68.

Bumpus, A. and D. Liverman (2008) 'Accumulation by decarbonisation and the governance of carbon offsets', Economic Geography 84 (2), 127-55.

Carvalho, A. (2007) 'Ideological cultures and media discourses on scientific knowledge: re-reading news on climate change', Public Understanding of Science 16, 223-43.

Carvalho, A. and J. Burgess (2005) 'Cultural circuits of climate change in UK broadsheet newspapers, 1985-2003', Risk Analysis 25 (6), 1,457-69.

Clarke, N., C. Barnett, P. Cloke and A. Malpass (2007) 'Globalising the consumer: Doing politics in an ethical register', Political Geography 26, 231-49.

Cosgrove, D.E. (1983) 'Towards a radical cultural geography: problems of theory', Antipode 15, 1-11.

Dalby, S. (2007) 'Anthropocene Geopolitics: Globalisation, Empire, Environment and Critique', Geography Compass 1, 1-16.

Davidson, A. (2007) 'Greening the Superbowl', Forbes Magazine, 19 January.

de Certeau, M. (1984) The practice of everyday life, translated by S. Rendall, Berkeley, CA: University of California Press.

Derrida, J. (1978) 'Structure, sign, and play in the discourse of the human sciences', in Writing and Difference, translated by Alan Bass, University of Chicago Press, 278-93.

Drury, I. (2008) 'Boris orders arts chiefs to stop "dumbing down" culture for young people', Mail on Sunday Online, 24 November, www.mailonsunday.co.uk/news/article-1088956/Boris-orders-arts-chiefs-stop-dumbing-culture-young-people.html (accessed 15 December 2008).

Eden, S., A. Donaldson and G. Walker (2006) 'Green groups and grey areas: Scientific boundary-work, nongovernmental organizations and environmental knowledge', Environment and Planning A 38, 1,061-76.

Entman, R. M. (1993) 'Framing: Toward Clarification of a Fractured Paradigm', Journal of Communication 43 (4), 51-58.

Forsyth, T. (2003) Critical Political Ecology: The Politics of Environmental Science, London: Routledge.

Foucault, M. (1977) Discipline and punish, translated by A. Sheridan, New York: Pantheon.

(1980) Power/knowledge, translated by A. Sheridan, New York: Pantheon.

Freudenburg, W.R., R. Gramling and D.J. Davidson (2008) 'Scientific certainty argumentation methods (SCAMs): Science and the politics of doubt', Sociological Inquiry 78 (1), 2-38.

Gelbspan, R. (1998) The Heat is On: The Climate Crisis, the Cover-up, the Prescription, Boston: Perseus Press.

Gieryn, T. (1999) Cultural boundaries of science: Credibility on the line, Chicago, IL: University of Chicago Press.

Global Cool (2009) 'About us', www.globalcool.org/about.

Goffman, E. (1974) Frame Analysis: An Essay on the Organization of Experience, Cambridge, MA: Harvard University Press. 
Goodman, M. (forthcoming) 'The mirror of consumption: Celebritisation, developmental consumption and the shifting cultural politics of fair trade', Geoforum.

Gottlieb, R. (2002) Environmentalism unbound: exploring new pathways for change, Cambridge, MA: MIT Press.

Guthman, J. (2007) 'The Polyanyian way?: Voluntary food labels and neoliberal governance', Antipode 39, 456-78.

Hall, S. (ed.) (1997) Representation: cultural representation and signifying practices, Thousand Oaks, CA: Sage.

Harvey, D. (1990) 'Between space and time: reflections on the geographical imagination', Annals of the Association of American Geographers 80, 418-34.

Hinton, E. and M. Goodman (forthcoming) 'Sustainable consumption: Developments, considerations and new directions', in G. Woodgate and M. Redclift (eds), International handbook of environmental sociology, 2nd edn, London: Edward Elgar.

hippyshopper.com (2008) 'Madonna on cover of green vanity fair. But why?', www. hippyshopper.com/2008/03/madonna_on_cover_of_green_vanity_fair_but_why.html.

Hobson, K. (2006) 'Bins, bulbs and shower timers: On the "techno-ethics" of sustainable living', Ethics, Environment, and Place 3, 317-36.

Holt, S. (2007) 'Can football save the planet?', BBC News online, news.bbc.co.uk/ sport1/low/football/6908507.stm (accessed 21 December 2008).

The Inspiration Room (2009a) 'Eric Prydz vs Floyd Proper Education', theinspirationroom.com/daily/2007/eric-prydz-vs-floyd-proper-education.

(2009b) 'The MTV Switch Green Song', theinspirationroom.com/daily/2008/mtvswitch-green-song.

James, D. (2006) 'Forget Joey's arse - it's wind turbines that matter', Guardian, 3 December, 30 .

Jenkins, H. (2006) Convergence culture: Where old and new media collide, New York: New York University Press.

Lieberman, B. (2009) 'Hollywood to the aid of serious science: pairing entertainment and drama with education', Yale Forum on Climate Change and the Media, 23 April.

Littler, J. (2008) "II feel your pain": Cosmopolitan charity and the public fashioning of the celebrity soul', Social Semiotics 18 (2), 237-51.

Luke, T. (2008) 'The politics of true convenience or inconvenient truth: struggles over how to sustain capitalism, democracy, and ecology in the 21st century', Environment and Planning $A$ 40, 1,811-44.

McChesney, R. (2008) The political economy of media: Enduring issues, emerging dilemmas, New York: Monthly Review Press.

McCright, A.M. and R.E. Dunlap (2003) 'Defeating Kyoto: the conservative movement's impact on U.S. climate change policy', Social Problems 50 (3), 348-73.

Marshall, P. D. (1997) Celebrity and power: Fame in contemporary culture, Minneapolis, MN: University of Minnesota Press.

Moser, S. and L. Dilling (eds) (2007) Creating a climate for change: communicating climate change and facilitating social change, Cambridge: Cambridge University Press.

MTV (2009) 'MTV networks international launches first youth-focused, global, multi-platform climate change campaign', MTV switch, www.mtvnetworks.co.uk/mtvswitch.

Norgaard, K.M. (2006) "People want to protect themselves a little bit": emotions, denial and social movement nonparticipation', Sociological Inquiry 76 (3), 372-96.

Oreskes, N., E.M. Conway and M. Shindell (2008) 'From Chicken Little to Dr. Pangloss: William Nierenberg, global warming, and the social deconstruction of scientific knowledge', Historical Studies in the Natural Sciences 38 (1), 109-52. 
Paterson, M. (2006) Consumption and everyday life, London: Routledge.

Popke, J. (2006) Geography and ethics: Everyday mediations through care and consumption, Progress in Human Geography 30 (4), 504-12.

(2009) 'Geography and ethics: non-representational encounters, collective responsibility and economic difference', Progress in Human Geography 33 (1), 81-90.

Prudham, S. (2007) 'The fictions of autonomous invention: accumulation by dispossession, commodification, and life patents in Canada', Antipode 39 (3), 406-29.

Redmond, S. and S. Holmes (2007) Stardom and celebrity: A reader, London: Sage.

Richey, L. and S. Ponte (2008) 'Better (RED) ${ }^{\mathrm{TM}}$ than dead: Celebrities, consumption and international aid', Third World Quarterly 29 (4), 711-29.

Robbins, P. (2001) 'Fixed categories in portable landscape: The causes and consequences of land cover categorization', Environment and Planning A 33 (1), 161-79. (2004) Political Ecology: A Critical Introduction, London: Blackwell Publishers.

Roddy, M. (2008) 'Skiers tell UN climate talks "save our snows", Reuters, 5 December, www.reuters.com/article/latestCrisis/idUSL5419888 (accessed 20 December 2008).

Rosati, C. (2007) 'Media geographies; uncovering the spatial politics of images', Geography Compass 1 (5), 995-1,014.

Sassatelli, R. (2006) 'Virtue, responsibility and consumer choice: Framing critical consumerism', in J. Brewer and F. Trentmann (eds), Consuming cultures, global perspectives: Historical trajectories, transnational exchanges, London: Berg, 219-50.

Schickel, R. (2000) Intimate strangers: The culture of celebrity in America, Chicago, IL: Ivan R. Dee.

Scott, D. and B. Jones (2006) 'The impact of climate change on golf participation in the Greater Toronto Area (GTA): a case study', Journal of Leisure Research 38 (3), 363-80.

Seabrook, J. (2000) Nobrow: The culture of marketing and the marketing of culture, New York: Vintage.

Seyfang, G. (2005) 'Shopping for sustainability: Can sustainable consumption promote ecological citizenship?', Environmental Politics 14 (2), 290-306.

Singer, S. (2002) 'Warrior One', Vogue, October.

Slocum, R. (2004) 'Polar bears and energy-efficient lightbulbs: Strategies to bring climate change home', Environment and Planning D: Society and Space 22, 413-38.

Street, J. (2004) 'Celebrity politicians: popular culture and political representation', The British Journal of Politics and International Relations 6 (4), 435-52.

Swyngeduow, E. (2007) 'Impossible sustainability and the post-political condition', in The sustainable development paradox: urban political economy in the United States and Europe, New York: Guildford Press, 13-40.

Weart, S. (2003) The discovery of global warming, Cambridge, MA: Harvard University Press.

Weiskel, T. (2005) 'From sidekick to sideshow: Celebrity, entertainment, and the politics of distraction', American Behavioral Scientist 49 (3), 393-409.

Whatmore, S. (2002) Hybrid geographies: Natures, cultures, spaces, London: Sage.

Wolff, A. (2007) 'Sports and global warming: as the planet changes, so do the games we play - time to pay attention', Sports Illustrated, 12 March, 36-45. 